\title{
LARREA Y PRADOS: LA POESÍA COMO MÍSTICA Y TRANSFIGURACIÓN
}

\author{
Tu as la plus belle façon de suivre l'exemple des fleuves \\ entre les pertes du ciel et l'égoïsme des îles \\ Ta paupière n'est pas encore à l'hauteur du dénouement des eaux \\ mais ça ne fait rien \\ JUAN LARREA, "Un faible pour la lumière"
}

Poco a poco Juan Larrea, en su doble dimensión de escritor y de promotor de importantes empresas culturales, ha logrado despertar la atención de críticos y especialistas sobre la poesía de las vanguardias españolas del primer tercio del siglo. Aunque reducida por lo que se refiere al número de poemas que la integran, su obra poética, escrita entre 1919 y 1932, y publicada en 1970 con el título de Versión celeste, resulta hoy material de lectura obligatorio y referencia imprescindible para la adecuada comprensión de algunos de los poetas que convencionalmente se integran en el grupo poético del 27. A ellos se adelanta en no pocas ocasiones Larrea por su mayor familiaridad con las corrientes poéticas europeas del momento, en especial por su profundo conocimiento de la poesía francesa ${ }^{1}$, un conocimiento que la mayoría de los poetas del grupo efectivamente habrán de tener, pero que lograrán más tarde; y que otros escritores del periodo simplemente no tuvieron. De todos ellos se diferencia también, no obstante, y entre ellos sobresale, porque Larrea es autor de una densa y rica labor crítica en prosa. Esta obra crítica ha sido desatendida, a pesar de la importancia indudable que tiene el que en ella se desarrollen ampliamente algunas de las creencias y principios de Larrea sobre la poesía y los poetas.

${ }^{1}$ Cf. Robert E. Gurney, "Larrea y la poesía francesa anterior al surrealismo", en J. M. Díaz de Guereñu (ed.), Al amor de Larrea, Pre-textos, Valencia, 1984, pp. 11-38. 
De entre los importantes trabajos que se han escrito sobre la obra de Larrea y, en concreto, sobre su noción de la poesía, destaca un conciso estudio del profesor David Bary por su loable precisión ${ }^{2}$. Partiendo de las manifestaciones del autor, recogidas en Versión celeste, el profesor estadounidense indica que en Larrea parece haber existido siempre interés por un arte vitalmente comprometido, esto es, un arte que exprese actualidad, pasión íntima y orientación hacia el conocimiento. El artista, ha escrito Larrea, será aquél que "generosamente se inmole a la atracción y repulsión que entre sí experimentan inteligencia y sensibilidad ${ }^{3}$. La poesía es para él una mística. "Mística lírica" era precisamente el título de uno de los capítulos de Orbe, libro de ensayos que no pudo publicarse a causa de la guerra civil, pero a cuyo original parece haber tenido acceso el profesor Bary, y donde Larrea indica que el poeta debe jugarse "a sí mismo al azar del idioma". Además, puesto que, según el poeta vasco, forma y fondo en el poema están tan íntimamente ligados que no es extraño que con frecuencia se confundan uno con otro ${ }^{4}$, entonces no sorprende que, en su opinión, en el poeta verdadero la disgregación del lenguaje como sintaxis y como entidad corresponda a la disgregación del ser expresivo. La poesía, dice, es al mismo tiempo lucha y colaboración, la misma actividad - añade, con poderosa imagen, en otro lugar- "que enemista dos palabras en el cráneo del poeta y obliga a todo el idioma a entrar en ebullición" 5 , imagen que va más allá de los "cortocircuitos en las frases" y el "cataclismo en la gramática" de que había hablado Huidobro en el canto III de Altazor, y que habían de ser tan del gusto de los creacionistas de las primeras décadas de siglo.

La concepción de la poesía como disgregación del ser aparece pronto en Larrea. Bary la localiza en un poema de 1917, inédito hasta que él lo recogió en Nuevos estudios. . . , que fue escrito por el poeta vasco durante la crisis sufrida mientras estudiaba en el internado que los padres jesuitas tenían entonces en Miranda de Ebro. Dice el poema:

${ }^{2}$ Me refiero a sus Nuevos estudios sobre Huidobro y Larrea, Pre-textos, Valencia, 1984, pp. 107-123.

3 JuAn Larrea, Versión celeste, Barral, Barcelona, 1970, p. 311.

${ }^{4}$ Cf. Orbe, apud David Bary, op. cit., p. 111.

${ }^{5}$ Versión celeste, p. 309. 


\section{TRANSCARNACIÓN}

Qué viejas sois, qué viejas sois, mis manos.

Qué viejas ya cuando os heredé...

$\mathrm{Y}$ vosotros, mis pies, qué cansados de errar itinerarios...

$\mathrm{Y}$ vosotros, mis ojos, qué de cosas no habréis visto que yo he llegado tarde para ver.

Y tú, sobre todo tú, mi corazón...

Cuánto habrás brincado como a la comba, con tu lazada azul, al compás de tu vieja canción.

¡Qué viejo eres, mi corazón!

\section{Sin conoceros} os compadezco, mis herederos, los que heredéis la triste herencia de mi carne, de mis pies, de mis ojos, de mis manos, cada vez más viejos...

Mas sobre todo a quienes heredéis mi corazón, os tengo, en verdad, compasión ${ }^{6}$.

A pesar de ser un poema temprano, en este texto aparece ya la noción del ser como ente disgregado, la cual sería más tarde desarrollada por Larrea en su obra ensayística. Si es permitida por un momento una analogía entre el cuerpo y la literatura, puede decirse que, si en ésta la tradición es asumida como corpus heredado, el ser físico es para Larrea herencia orgánica - pies, manos, ojos-y espiritual - metafóricamente hablando, el corazón. Es, por tanto, un cuerpo heredado cuyo conocimiento es anterior a su encarnación en el "yo" del poeta. De ahí que los ojos hayan visto algo que el poeta dice haber llegado tarde para ver, que el corazón haya vivido y sea ya viejo, etc. El corpus literario se trans- 
fiere a la tradición y, de modo análogo, el cuerpo es transferido más tarde, esto es, "transcarnado". Comentando el título del poema, Bary indica que, en su violento neologismo, une espíritu y carne, haciendo corresponder por tanto miembros y sentimiento en una sola palabra, y es posible ver que en él "está en germen su deseo de liberarse de la personalidad individual. . . ya parecida a la que lo caracterizaría en lo porvenir"'

Importa añadir ahora que en esta formulación de la crisis poética como "transcarnación" puede verse la primera formulación del concepto "transfiguración"', concepto de fundamental importancia para entender la poética de Larrea, un aspecto ya notado por Bary quien, apropiadamente, tituló su primer libro Larrea, poesía y transfiguración ${ }^{8}$. Es, asimismo, una noción fundamental para entender su teleología de la cultura y, en particular, su milenarismo, pues Larrea asume que la cultura está guidada por un telos hacia un fin definible como una realidad nueva que habrá de darse “transfigurada”. Como ha indicado Díaz de Guereñu", Larrea es un peregrino en busca de la nueva polis, explorador de la nueva ciudad de Dios, a la que él se refiere como la nueva madre en su ensayo “Ingreso a una transfiguración”, publicado como prólogo a Jardín cerrado de Emilio Prados. En este escrito habla de este nuevo orden como "ciudad translúcida - madre sin rotura ni mancha - sin noche, y por tanto sin templo... en la que se ve a Dios cara a cara'"10. Conceptos sinónimos a éstos recurren en toda la obra de Larrea, y son fundamentales para entender su poesía, pues con ellos el poeta expresa su anhelo por llegar a un más allá liberado de materialidad, en pura comunicación con lo absoluto: el poeta vasco dice sentirse guiado por un "impulso incoercible hacia una universal e intrínseca allendidad"'11, pues su empeño es "quebrar el aro del horizonte"'12.

Importa ahora estudiar el prólogo que escribe Larrea para Jardín cerrado, pues este texto permite considerar uno de los puntos esenciales indicados al comenzo. En concreto, permite contemplar hasta qué punto Larrea es importante para el desarrollo del

7 Ibid., p. 102.

8 D. BARY, Larrea, poesía y transfiguración, Planeta, Barcelona, 1976.

9 Cf. "El poeta en Juan Larrea", en Al amor de Larrea, pp. 65-82.

${ }^{10}$ Larrea, "Ingreso a una transfiguración"', en E. Prados, Poesias completas, Aguilar, Madrid, 1976, t. 2, p. 12.

11 Versión celeste, p. 43.

${ }^{12}$ Ibid., p. 23. 
universo poético de Emilio Prados. De hecho, como intentaré mostrar a continuación, este prólogo importa porque algunos aspectos fundamentales de la poesía pradiana se aclaran a la luz de la teoría místico-poética de Larrea. Este prólogo del autor vasco permite entender, en definitiva, el empeño orgánico visible en la última poesía de Prados, un empeño ya anunciado por Larrea en 1946, y que habría de culminar el malagueño más de quince años después con la poesía trasterrena posterior a La piedra escrita.

En el prólogo mencionado, además, recurren importantes nociones de la teoría poética de Larrea. Éste compara Jardín cerrado con una simiente y con un ataúd, considerándolo de este modo, simultáneamente, muerte y vida, desintegración necesaria y previa a la reintegración del ser expresivo del poeta. Habla después del volumen de poemas como "poética incorporeidad que vaga por otro mundo". E, inmediatamente, añade: "Vaga entre el ser y el no ser por regiones difícilmente accesibles donde, no la conciencia del poeta sino el universo entero, parece haberse desmaterializado"13. Trabajando con conceptos e imágenes que nos acercan al poema de 1917, "Transcarnación", Larrea indica que, en realidad, en Jardín cerrado no se da una integración del individuo en el ser colectivo, sino que lo que se manifiesta en esta poesía es "la conciencia de un pueblo que se desensimisma" 14 . De este modo, la España peregrina vuelve a incorporarse al mundo, mejor dicho, al nuevo mundo, "transfigurada"15.

Esta noción de pueblo desensimismado, y expresándose a través del poema, aparece en otros poetas españoles exiliados en México. Probablemente el caso más conocido sea el de León Felipe. En Ganarás la luz, éste adopta la actitud del bardo, dueño de la palabra, frente a los vencedores de la contienda, dueños de la espada, un fenómeno estudiado en detalle por Ciplijauskaité16.

Soldado, tuya es la hacienda, la casa, el caballo y la pistola.

13 "Ingreso...", p. 11.

${ }^{14}$ Ibid., p. 14

${ }^{15}$ Ibid., p. 19

16 Véanse los trabajos de Biruté CiplijausKaité, La soledad y la poesía es pañola contemporánea, Ínsula, Madrid, 1962, pp. 182-225; y El poeta y la poesía, Insula, Madrid, 1966, pp. 245-271. 
Mía es la voz antigua de la tierra.

Tú te quedas con todo y me dejas desnudo y errante por

Mas yo te dejo mudo... ¡mudo!

[el mundo...

y ¿cómo vas a recoger el trigo

y a alimentar el fuego

si yo me llevo la canción? ${ }^{17}$

Conjetura es, ciertamente, pero no por ello resulta menos destacable el que Ganarás la luz esté dedicado a Juan Larrea, y que en él haya rasgos indudables del milenarismo de éste, cuando León Felipe dice que "la España que se llevó la canción, cree que la religión de mañana será la Poesía viva y libre, y con una dimensión nueva"'18. A León Felipe, por otra parte, recuerda Larrea en el prólogo mencionado al libro de Prados, subrayando el deseo expreso en la poesía de aquél de unlversalizarse, proceso que el autor de Versión celeste define como "negocio de muerte y transfiguración"'19.

En Jardín cerrado, además, Larrea nota indudables huellas de misticismo. Pero, correspondiendo con el proceso de desintegración y reintegración antedicho, no es éste un misticismo tradicional, la noche oscura del alma de San Juan, sino que en el autor de Cuerpo perseguido se observa, según Larrea, la "noche oscura del cuerpo"'20. Este hecho lleva al vasco a manifestar que "hemos perdido nuestro cuerpo habitual [...] y andamos entre las malezas de la angustia, a orillas de la Nada, rastreándola'”21, palabras que hacen eco indudablemente a la intuición original que se expresaba en el poema larreano de 1917, citado más arriba. Por tanto, cabría preguntarse ahora de quién está hablando aquí Larrea en realidad, si de la poesía de Prados o, por el contrario, exponiendo sus propias convicciones sobre la poesía. De hecho, a orillas de la Nada se había situado el autor de Versión celeste en alguno de sus poemas: "Verde de mar o sobre todo o nada / al borde del abismo de los oscuros labradores / nuestra suerte está echada"'22.

Por otra parte, no hay novedad sustancial en esta Nada pra-

${ }^{17}$ León Felipe, Ganarás la luz, Finisterre, México, 1974, p. 29.

18 Ibid., pp. 28-29.

19 "Ingreso...", p. 20.

20 Ibid., p. 12.

21 Ibid., p. 13.

${ }^{22}$ Versión celeste, p. 71. 
diana, pues ya Alberti se había enfrentado a ella cara a cara en Sobre los ángeles. Desde los versos iniciales del primer poema, " $\mathrm{Pa}$ raíso perdido", el poeta se expresa en términos que resultan inconfundibles:

A través de los siglos, por la nada del mundo, yo, sin sueño, buscándote ${ }^{23}$.

No obstante, lo que sí resulta novedoso en Prados, y debió de resultar asimismo singularmente atractivo para Larrea, es la resolución mística de una crisis profunda que, si bien había afectado a otros miembros del 27, en Prados se resolvía de modo diferente, por la singular riqueza interior que el poeta consigue a base de renunciar al "yo" - riqueza y renuncia ya visibles en su libro anterior, Mínima muerte (1944) - y a la consiguiente renuncia a la voluntad, lo cual hace posible, como afirma Larrea en su teoría sobre el poeta, el nacimiento de un nuevo ser. En "Mística lírica" había dicho éste que el poeta debía: "Jugarse a sí mismo al azar del idioma, hacerse una voluntad fuerte para encontrar a cada instante la manera de sacrificar esa misma voluntad"'24. Y, hablando de Rimbaud, había destacado la ausencia de tal renuncia como motivo del fracaso del poeta de Une saison en enfer:

Con el caso de Rimbaud asistimos al caso contrario a nuestros místicos españoles. Un espantoso fracaso interior [ . . . ] le hizo desaprovechar la quizá más grande riqueza verbal conocida. En cambio nuestros literatos, a fuerza de riqueza interior, consiguieron manejar un idioma con la más adorable y perfecta desenvoltura ${ }^{25}$.

Pero importa destacar también que la resolución indicada más arriba se produce de modo inconsciente en Prados pues, según escribe Larrea en el prólogo a Jardín cerrado:

Las prodigiosas, las aparentemente desatinadas intuiciones de Emilio Prados coinciden de modo exactísimo con todos estos conceptos poéticos fundamentales que, según consta al que esto escribe, ignoraba el poeta prácticamente en absoluto ${ }^{26}$.

${ }^{23}$ Rafael Alberti, Poesía (1924-1967), Aguilar, Madrid, 1972, p. 317.

${ }^{24}$ Apud BaRY, Nuevos estudios, pp. 110-111.

${ }^{25}$ Ibid, , pp. 116-117.

26 “'Ingreso...", p. 22; las cursivas son mías. 
Dicho de otro modo, lo que atrajo a Larrea era ver realizados, mediante una serie de "intuiciones aparentemente desatinadas", sus propias nociones sobre la poesía, unas nociones de las que Prados, según indica expresamente Larrea, no era consciente en absoluto. Por tanto, puede añadirse ahora que el título del prólogo de Larrea, "Ingreso a una transfiguración", ha de ser entendido en su doble valor de introducción o presentación de cara al lector (e, incluso, al autor mismo, Prados), y de inicio de una actividad por medio de la cual se llegaba a un lenguaje capaz de nombrar una realidad renovada.

Efectivamente era eso, ya que Larrea, por un lado, introduce al lector a un mundo de intuiciones aparentemente caóticas y supuestamente carentes de sentido porque, al ser un lenguaje nuevo o extraño, dichas intuiciones debían ser traducidas convenientemente para hacerlas asequibles a dicho lector; o, dicho de otro modo, hacerlas inteligibles en el lenguaje ordinario. Era además, por otro lado, una especie de razón de fe de algo que el visionario Larrea anunciaba como llevándose a cabo en la poesía española del exilio: en un libro de uno de sus representantes (y uno de sus representantes más anónimos, además, si se compara con otras figuras más conocidas como Alberti, Guillén, Salinas e, incluso, Cernuda) se había logrado penetrar en esa vía ascendente en busca de la ciudad milenaria, de la última luz, cuya raíz - Larrea lo indica en el prólogo- es la misma que la de la divinidad. Para decirlo con la peculiar y, en ocasiones, oscura terminología larreana, la vieja tierra castellana acababa de rendir espíritu - había dado a luz- en el universo americano: "Su relación poética de equivalencia con el todo cósmico nos ha sido suministrada impensadamente por Emilio Prados" "27; y poco antes, retomando la intuición del poema temprano, "Transcarnación", había dicho: "Le bastó a [...] Emilio Prados, sembrarse en esta nueva tierra, para sentirse poseído al margen de su voluntad, por un intenso vivir, ser adentro, prolongación del que ya traía vivido, pero en un nuevo, impensado y definitivo rapto" 28 . Consiguientemente, concluirá Larrea desarrollando una oposición entre literatura y poesía cuyos orígenes parecen ser unamunianos ${ }^{29}$; estamos "en presencia de un libro orgánico que, por encima de las virtudes líricas

${ }^{27}$ Ibid., p. 21.

${ }^{28}$ Ibid., p. 18.

${ }^{29}$ Cf. J. M. Díaz de Guereñu, "El poeta en Juan Larrea”, pp. 67-72. 
que lo adornan, constituye un fenómeno poético esencial" 30 .

La experiencia de Jardín cerrado habrá de ser de fundamental importancia para el desarrollo de la poética posterior de Prados. Por un lado, como ha señalado acertadamente Blanco Aguinaga, este libro "significa en la trayectoria poética de Prados esa armonía y equilibrio entre el pensamiento y su forma [...] con que va sellada toda gran poesía"'31. Pero es, además, el punto de partida de una ascensión antes tan sólo intuida, y que a partir de ahora se expresa en términos claros llevando, en libros sucesivos, hasta la poesía transparente que sigue a La piedra escrita. Escrita entre 1958 y 1960 , aunque contiene poemas anteriores ${ }^{32}$, la última parte de las ocho que integran La piedra escrita se compone de títulos significativos en función de lo dicho hasta aquí. "Transfiguración de lo visible" es el título de los dos primeros poemas, en los que se repite expresamente el concepto esencial de la poética de Larrea. El primero se abre con imágenes que expresan circularidad, la figura geométrica que corresponde no sólo al espacio infinito, sino también a la soledad que revela en el verso "una verdad del hombre íntimo"'33. Dice el poema:

Ancha llanura. Pensamiento en círculo.

(Principio y fin se unen a un solo abismo.)

Desde este espacio el poeta parte para expresar más tarde la elevación hacia la nueva realidad transfigurada:

¡Alta llanura!... (¿El valle es pensamiento?...)

La luz germina su esmeralda en vuelo ${ }^{34}$.

Corroborando esta transfiguración, en el poema siguiente, que tiene el mismo título que el anterior, se logra la quietud, la transparencia: “¡Albo y redondo el mundo es templo!” $(P C$, p. 833).

30 "Ingreso...", p. 24.

31 Carlos Blanco Aguinaga, "Emilio Prados. Vida, obra. Antología", RHM, 26 (1960), 3-4. Véase, además, P. J. Eluis, The poetry of Emilio Prados. A progression towards fertility, University of Wales Press, Cardiff, 1981.

${ }^{32}$ Cf. la ed. de La piedra escrita, de J. Sanchis-Banús, Castalia, Madrid, 1979, pp. 57-66.

33 Gaston Bachelard, La poética del espacio, FCE, México, 1975, pp. 271-272.

${ }^{34}$ Emilio Prados, Poesías completas, t. 2, p. 831. En adelante cito por $P C$ en el texto seguido del número de página. 
El poema central de esta última parte de La piedra escrita se titula "Cambios de amanecer"; en él se enuncia la nueva morada, situada en la nueva polis larreana ("La ciudad abierta"' se subtitula otra de las partes del volumen). Aquí reaparecen imágenes de Jardín cerrado:

¡Árbol violento mana

del poniente en la noche! [...]

En jardín a la vista,

árbol violento es daga

del poniente.

$$
(P C, \text { p. 835). }
$$

De este modo se llega al fin jubiloso del último verso con la exclamación: “¡Morada sin reposo!” ( $P C$, p. 836).

Finalmente, esta parte se cierra con otros dos poemas, ambos titulados "Realización del mito". Esto es, si mi interpretación es correcta, encuentro de la nueva realidad soñada, un encuentro que se expresa igualmente de modo jubiloso, con exclamaciones yuxtapuestas, como si, parafraseando lo dicho más arriba respecto a la poética de Larrea, a la disgregación del ser correspondiera la disgregación de la sintaxis, y el lenguaje, en fin, quedara reducido a expresiones parentéticas y exclamativas sin nexo o coordinación alguna:

¡Duerme el mundo partido hacia adelante!

¡Vela la sombra interna! ¡La luz nace!

$$
(P C, \text { p. 839). }
$$

Momento este, además, de realización y reintegración, a que Larrea había aludido al hablar del "árbol de la cruz, ara donde a los cuatro horizontes se verifica la muerte mística, trampolín para el salto mortal que trasciende el Paraíso"'35. Así precisamente concluye el poema, haciendo uso de un lenguaje en el que las repeticiones parecen manifestar la identidad de los conceptos, en particular en la expresión de la luz y de la mencionada trascendencia del árbol, ya transfigurado en cruz y nuevo ser, realización del mito:

¡Gozo de estar! ¡La luz en la luz luce!

¡Entra a la luz! ¡Grabada en la luz fluye!

35 “Ingreso...", p. 14. 
¡Cambio al nacer!...

$$
\text { (¿Revelación es cambio?...) }
$$

¡Descansa el mito en luz crucificado!

$$
\text { (PC, p. 840). }
$$

En correspondencia con lo anterior, quisiera añadir que el libro siguiente, titulado Signos del ser, que en otro lugar he denominado poesía trasterrena con el fin de aludir a la transición hacia la transparencia definitiva que en él se $\mathrm{da}^{36}$, contiene elementos que nos devuelven una vez más a las nociones poéticas antes vistas al hablar de Larrea. Señalaré en este sentido un dato, en apariencia insignificante, pero que permite ver, creo, la indudable integración de las nociones larreanas en la poesía posterior de Prados. En nota a pie de página a su introducción a Jardín cerrado, y como corroboración factual de su teoría sobre el nuevo orden que el vasco identifica con América como madre esencial ("No somos ya nosotros los que vivimos fuera de la Madre [...] es la Madre [... ] la que, al morir en sí, permanece viviendo en nosotros'), Larrea dice lo siguiente: "Para medir el alcance concreto y la calidad de experiencia vivida de esta poética realidad, no estará de más advertir que Emilio Prados ha entregado a la tierra americana a su propia madre[... ] estando este libro ya en prensa'" ${ }^{37}$. Pues bien, Signos del ser está dedicado a la memoria de la madre del poeta. Este hecho, en apariencia trivial, importa por la forma en que esta dedicatoria está escrita, pues en su redacción - "A mi madre en su tierra" ( $P C$, t. 2, p. 843; subrayado mío)- reverbera la anotación larreana mencionada, la noción larreana de que los cuerpos han de sembrarse en nueva tierra, "negocio de muerte y transfiguración'.

Conviene subrayar, además, el sentido de esta dedicatoria que, como se ha dicho, está vinculada a la simbología larreana. En un ensayo que tuvo gran influencia en la crítica literaria española desde los años sesenta, Dámaso Alonso estableció una diferencia entre "poetas arraigados" y "poetas desarraigados". Conviene recuperar esta clasificación y hacer uso por un momento de los conceptos del maestro de la estilística. Este decía que los poetas arraigados nos ofrecen "unas cuantas imágenes del mundo, muy armónicas o bien centradas, o vinculadas a un ancla, a un fijo

${ }^{36}$ IgNACIO-JaVIer LóPez, "Reoetición e integración en la obra poética de Emilio Prados", BHS, 62 (1985), p. 382.

37 "Ingreso...", p. 21; las cursivas son mías. 
amarre"'; para los desarraigados, en cambio, "el mundo [...] es un caos y una angustia, y la poesía una frenética búsqueda de ordenación y ancla"38. Entre los primeros incluía a Guillén, Panero, José María Valverde y José Antonio Muñoz Rojas; entre los segundos sobresale el nombre de Blas de Otero, "quien con más lucidez [.. . ] ha expresado [ . . . ] los datos esenciales del problema del desarraigo" 39. Como ilustración de este segundo tipo de poesía, la "desarraigada", Alonso cita los versos iniciales de Ángel fieramente humano, de donde parece haber tomado el concepto mismo:

Un mundo como un árbol desgajado

Una generación desarraigada.

Unos hombres sin más destino que apuntalar las ruinas ${ }^{40}$.

Importa, para la hipótesis aquí desarrollada, el primero de los versos citados, fundamentalmente porque es un símbolo que también aparece en Prados con un sentido similar al que tiene en el poema de Otero. A este respecto Larrea escribe: "Todo en este Jardín Cerrado [sic] gira en torno de un árbol que, cuando bien lo singularicemos, resultará el árbol de la Vida. Ese Árbol [...] es el hombre [...] es el pueblo mismo" "41. Es también un árbol -en sus dimensiones de vida, hombre y pueblo- que ha arraigado (más propiamente, que ha comenzado a arraigar finalmente) en la nueva tierra o, para repetir las palabras que aparecen en la dedicatoria de Signos del ser, ha comenzado a arraigar "en su tierra". La dedicatoria a la madre del poeta al frente de este libro es, pues, una indicación de este tránsito al nuevo espacio: un lugar al que el poeta arriba tras la experiencia poético-mística de los libros anteriores.

En función de lo anterior, puede decirse que, hasta cierto punto, toda la poesía que Prados escribe en el exilio supone una búsqueda de arraigo. Primero en la tierra americana; y, más tarde, en una tierra sin tierra, en una realidad transfigurada. Blanco Aguinaga ha descrito el primero de estos procesos, destacando la

38 DÁmaso Alonso, "Poesía arraigada y poesía desarraigada", en Poetas españoles contemporáneos, Gredos, Madrid, 1965, pp. 345 y 349.

39 Ibid., p. 351.

40 Blas DE OTERo, Ángel fieramente humano. Redoble de conciencia, Losada, Buenos Aires, 1973, p. 11.

41 "Ingreso...,", p. 14. 
importancia de un poema de Penumbras I, titulado "Vuelta a México", como expresión del primer momento del hallazgo de la nueva realidad ${ }^{42}$. En este poema Prados habla de dos paisajes, uno recién descubierto ("“Todo el campo era una:joya!"), el otro intuido todavía, naciendo:

(Otro paisaje, en mi pecho, iba encendiéndome el día, también a medio lograr por mi memoria perdida...)

$$
\text { (PC, t.1, p. 780). }
$$

Quisiera detallar ahora ejemplos correspondientes al segundo proceso mencionado, ejemplos que proceden de Sonoro enigma, primer libro publicado por Prados en España tras la guerra, aparecido en Papeles de Son Armadans en 1958 ${ }^{43}$. Partiendo de motivos tradicionales en la poesía española (se citan versos de Quevedo, San Juan de la Cruz y Jorge Manrique), el poeta expresa el peso de la tradición, entendido éste como un elemento que ha acabado por integrarse en su propia voz, incluso en el silencio trasterrado del exilio:

¿Qué peso oscuro, luz, como un silencio desalado, tira de mí hacia el fondo de tu velocidad, y me unifica en sólo un acto de su cuerpo?

$$
\text { (PC, t. 2, p. 679). }
$$

Esta voz se integra en la del poeta de un modo análogo a como el cuerpo de Larrea era sentido, en el poema "Transcarnación", en tanto que herencia, es decir, en tanto que corpus-cuerpo transmitido y transmisible. Así, dice Prados:

Sin forma estoy tendido, aislado al pensamiento que enlazaba mi destino a tu paz. Sin tu armonía -en luz latente - tiempo soy de un canto ajeno a mí y en movimiento. Giro denso con él y hundido estoy

42 Carlos Blanco Aguinaga, art. cit., pp. 62-63.

${ }^{43}$ Poesías completas, t. 2, pp. 677-686. 
al centro, tan contrario, de su memoria que, presencia real de mí, mi ausencia en él, es unidad que me ha robado.

Posteriormente, en el mismo poema, reelaborando los versos " $\mathrm{iAh}$ de la vida! ¿Nadie me responde?...", de Quevedo, el poeta, sintiéndose ya integrado por la tradición - "olvidado" en ella con el olvido ("Quedéme y olvidéme") de San Juan- concluye:

Olvidado, recupero

de mi unidad la luz, y veloz subo

en ella y le respondo:

¡Ah de la vida!

Este mismo olvido, en fin, e idéntica integración aparece en otro poema del volumen, en el que los versos reelaborados son esta vez de San Juan:

sin condición, un mundo entre sus nombres habla - sus nombres atravieso- y siento...

"Un no sé qué que quedan balbuciendo".

$$
\text { (PC, p. 684). }
$$

Finalmente, la "transcarnación", en su reformulación larreana como "transfiguración", aparece en los poemas del último libro de Prados, que recibió el título póstumo de Cita sin límites. En él las nociones larreanas, expresadas en el prólogo a Jardín cerrado, "Ingreso a una transfiguración", son ya elaboradas de un modo consciente. Dice el poeta, en el poema "A veces voy despierto... ", fechado el 12 de diciembre de 1961, y réplica poética de "El dormido en la yerba" de Jardín cerrado, lo siguiente:

Me he dado a luz, sin piel, múltiple e inconforme.

un enjambre espesísimo de razas

- momento de hoy-,

trozo colgante en plena vida abierta soy.

El estar no lo siento.

Me cerraron los ojos: no los tengo.

Mi pensamiento fue libado en color, 
en ausencia, en mancha ciega, en vibración de espalda.

Así voy por la calle despierto.

$$
(P C, \text { p. 987). }
$$

Asumiendo, por último, el momento de la muerte como momento de encuentro de la luz - y no se olvide que la raíz de la palabra "luz" es, según Larrea, la misma que la de "divinidad": "Recuérdese que la raíz Div, de donde provienen nuestras palabras Dios y Divinidad, significa luz" 44 -, el poeta aparece finalmente despierto en los versos siguientes:

La luz me ha dado en ella así:

sin piel, elaborado en un espejo.

$$
\text { (PC, p. 987). }
$$

Debe mencionarse, no obstante, que este desenlace ya había sido anticipado por Larrea en su prólogo de 1946, donde dice:

Todo ello [el mundo presentado en el conjunto de imágenes de Jardín cerrado] constituye un complejo orgánico de metamorfosis que, con miras al despertar, cruza coordenadamente las regiones humanas más recónditas, hasta dar con el punto donde efectúa su cometido instrumental la muerte $e^{45}$.

Para concluir, la importancia de la figura de Juan Larrea para el correcto entendimiento de algunos de los poetas del grupo del 27 ha sido repetida en numerosas ocasiones. No obstante, estas afirmaciones tenían en cuenta prioritaria, y a menudo exclusivamente, la poesía del visionario vasco, conocida de los demás autores por los poemas que éste publica en Favorables París poema, Grecia, Carmen y otras importantes revistas de poesía del periodo. Sin negar esta influencia, que hubo de existir, creo que, como se ha intentado mostrar anteriormente, cabe hablar de otra influencia más directa a través de la teoría poética del autor de Versión celeste.

La importancia de dicha teoría en el caso particular de Prados es obvia, resultando particularmente significativa a partir de

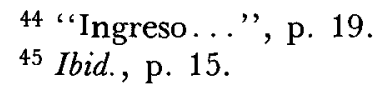


1946. El prólogo que Larrea escribe para Jardín cerrado permitió que lo que anteriormente se presentaba como "prodigiosas [pero] desatinadas intuiciones" en la poesía del malagueño, fuera finalmente desarrollado de un modo orgánico. En los libros finales de Prados, sin duda alguna los más orgánicos de su producción, la presencia de conceptos poéticos larreanos es evidente, y una lectura de la poesía del autor de La piedra escrita que preste atención a dichos conceptos habrá de ser sin duda fructífera para desentrañar unos textos que, de otro modo, resultan a menudo oscuros $\mathrm{y}$, en ocasiones, casi impenetrables.

IGNACIO-JAVIER LÓPEZ University of Virginia 